\title{
DIÁLOGO INTERCULTURAL ¿UNA UTOPÍA DEL SIGLO XXI?
}

\author{
M $^{\mathrm{a}}$ CARMEN LÓPEZ SÁENZ1 \\ UNED. Madrid
}

\begin{abstract}
RESUMEN: Una vez aclarado qué entendemos por «utopía», adoptaremos la actitud fenomenológica para buscar el sentido de la interculturalidad en nuestro universo multicultural. Éste pierde su indiferencia cuando es comprendido e incorporado a nuestra praxis, gracias a la interculturalidad, la cual es, ante todo, un desafío moral. La centralidad del diálogo en la hermenéutica filosófica presta dinamicidad a este fenómeno. Nuestro ejercicio hermenéutico reactivará la fenomenología de la intersubjetividad como origen de la vida social y del encuentro entre culturas. Concluiremos defendiendo la necesidad de restaurar una universalidad concreta para que el multiculturalismo no se disuelva ni en el relativismo ni en el culturalismo y adquiera sentido como interculturalidad. No llegamos a ella espontáneamente, ni negando la cultura propia y adhiriéndonos a las otras, sino formándonos y configurándola en común conscientemente como proceso de identificación consciente en el seno de las diferencias.
\end{abstract}

PALABRAS CLAVE: Interculturalidad, multiculturalismo, fenomenología, hermenéutica, intersubjetividad.

\section{Intercultural Dialogue. A Utopia of 21 st Century}

\begin{abstract}
Having clarified what we mean by «utopia», we adopt the phenomenological attitude in order to search for the meaning of interculturalism in our multicultural world. The latter loses its indifference when it is understood and incorporated into our praxis thanks to multiculturalism, which is primarily a moral challenge. The centrality of dialogue in philosophical hermeneutics lends new energy into this phenomenon. Our hermeneutic exercise is going to reactivate the phenomenology of intersubjectivity as the origin of social life as well as the source of the encounter between cultures. We will conclude by defending the need to restore the concrete universality so as not to dissolve multiculturalism neither into relativism nor into culturalism; in this way, multiculturalism acquires meaning as interculturalism, which is not attained neither spontaneously nor by adhesión to the other cultures after denying the our own. We reach interculturalism by building ourselves and by configuring it together consciously as a process of identification within differences.
\end{abstract}

KEY WORDS: Interculturalism, multiculturalism, phenomenology, hermeneutics, intersubjectivity.

\section{INTRODUCCIÓN}

Fenomenología y hermenéutica son filosofías esencialmente interculturales. No se limitan a yuxtaponer diferentes tradiciones, sino que reflexionan sobre el «entre», sobre la cualidad de los intercambios culturales que tienen lugar en el mundo de la vida. Por ello, pensamos, a diferencia de Wimmer (2004), que no es preciso desarrollar nuevas teorías para el entendimiento intercultural, sino hacer operantes conceptos que nos permitan comprender el fenómeno de la multiculturalidad, ante todo, la razón que permea todas las culturas, una razón

1 Este trabajo se ha realizado en el marco del proyecto de investigación FFI2012-32575. 
entendida como telos de la humanidad, como sentido de cada tradición que opta por la vida consciente de la humanidad que se comprende,

(...) comprendiendo que es racional en el querer-ser-racional, que esto indica y quiere decir una infinitud de la vida y de la tensión hacia la razón, que Razón justamente significa lo que el ser humano en tanto que tal desea en lo más íntimo, lo que puede satisfacerle, hacerle «feliz» (Husserl [1954] 1976: 275).

Este telos racional se va haciendo histórica e interculturalmente. No es necesario sobrevolarlo mediante la construcción de una razón intercultural que interseccione con otras; más bien, hay que comprender la tendencia a la unidad — no a la uniformidad - de la razón en sus múltiples voces.

La razón fenomenológica, especialmente en su deriva hermenéutica, es ya intercultural, porque es constitutivamente dialógica: toma conciencia de las limitaciones, estudia las razones teórico-prácticas del diálogo, sus sujetos intencionalmente dirigidos al mundo y a los otros, la intersubjetividad transcultural, las interrelaciones comunicativas ${ }^{2}$ y, en suma, la vida de la comunidad de personas que se pone de manifiesto en su experiencia.

Nuestra propuesta es integrar la interculturalidad en el proyecto de una fenomenología de la razón ampliada a lo que secularmente fue excluido de ella, que complete la descripción de la experiencia con la reflexión sobre su sentido, para entender el «universal lateral», que adquirimos a través de la experiencia de otras culturas y de la incesante confrontación del yo en los otros y viceversa. El diálogo es la manifestación de esta dinámica comunicativa por la que se desarrolla la relación entre interioridad y exterioridad, apropiación y desapropiación, tan necesaria para la interculturalidad. Ahora bien, ¿el diálogo intercultural es una utopía o una ideología enmascaradora de la realidad?33

\section{IdEOLOGÍA Y UTOPÍA}

Este es el título del libro de K. Manhein (1929) en el que, a pesar de considerar que ideología y utopía son distorsiones de la realidad, las diferencia en razón de que la ideología mantiene la situación social existente, mientras que la utopía trata de transformarla de manera radical.

P. Ricoeur, en cambio, las considera complementarias para interpretar la realidad, si bien el pensamiento utópico presta a la ideología un género semántico, una narratividad; además, los modelos ideales de sociedad son puntos de referencia de las diferentes ideologías políticas.

2 La interculturalidad comunicativa como dialéctica entre identidad y diversidad ha sido desarrollada en PenAs and López (2006).

3 Habermas ha criticado la concepción armonizadora del mismo llevada a cabo por GADAMER, en razón de su carácter ideológico, Cf. LóPEz, 2012c: 734-750. 
La ideología presenta una acepción positiva y otra negativa y deformadora; lo mismo sucede con la utopía: ésta es positiva cuando se la entiende como lo no existente que permite atisbar reflexivamente lo posible; en cambio, la utopía negativa es la que pretende fabricar un mundo nuevo empleando la violencia para anular el establecido.

Mi hipótesis sostiene que hay un aspecto positivo y un aspecto negativo en la ideología y en la utopía y que la polaridad entre estos dos aspectos de cada término puede esclarecerse explorando una análoga polaridad entre los dos términos. Creo que esta polaridad entre ideología y utopía y la polaridad que hay en el seno de cada una de ellas pueden atribuirse a ciertos grados estructurales de lo que he llamado imaginación cultural. (Ricoeur [1986] 1994: 45-46).

Siguiendo a C. Geertz, Ricoeur entiende la ideología como sistema cultural necesario para la integración social. Le atribuye un carácter dinámico o generativo que estaría en la base de la motivación de los individuos y de la praxis social. Por el contrario, el marxismo ha denostado la ideología por considerarla encubridora de la verdadera realidad social que radica en la infraestructura. Desde la perspectiva ricoeuriana, el error de esta aproximación residiría en su identificación de la ciencia con el verdadero conocimiento y en su ceguera ante la constitución simbólica de la realidad social. Sólo abriendo los ojos a ella, se puede entender que sea susceptible de deformación ideológica.

Ricoeur no contrapone la ideología a la ciencia, como hace el marxismo, sino que la relaciona con la praxis, frente a la techné. Explica cómo opera a través de la materialidad de la acción simbólica, la cual media entre los intereses y las formas de representación de la imaginación. La ideología es tan capaz de integrar a los componentes de la sociedad como de ejercer el dominio sobre ellos; lo hace, generalmente, sin que tengamos conciencia explícita de ello; en otras palabras, pensamos desde ella más que sobre ella.

Al igual que Gadamer y a diferencia de Habermas, Ricoeur sabe que la ideología no es completamente accesible a la reflexión crítica; es decir, aunque nos propongamos analizarla, nuestros juicios e interpretaciones nunca serán los del observador externo e imparcial, pues siempre estarán dentro de la realidad social que pretendemos conocer. La razón crítica nunca llegará a ser reflexión total, porque el distanciamiento es tan sólo un momento de la pertenencia y ésta también es obra de la razón común. Por este motivo, Ricoeur se distancia de la ideología crítica de la Escuela de Frankfurt. Como esta última, nosotros, entendemos la utopía no como un sueño imaginario, sino como crítica de las insuficiencias de la situación establecida y superación (Aufhebung) de la misma con el apunte de algo mejor. Así hay que entender el negativismo de estos filósofos, como utopía que, al menos, se libera de esa lógica infernal que reduce las ideas a aporías de lo existente:

La fidelidad a la utopía se despliega en un continuo ejercicio crítico en el cual se enfrenta y se examina el presente a partir del futuro. Se subordina resueltamente, lo que es a lo que no es. Lo mejor, hacia lo que tiende la razón utópica es lo que se presenta como ausente (Perlini 1976: 38). 
En 1967, Marcuse impartió una serie de conferencias en la Universidad Libre de Berlín, que dieron lugar al libro El final de la utopía. Como los otros frankfurtianos, consideraba que la utopía comenzaba por el negativismo que está a medio camino del pesimismo y del optimismo, pero que no es sinónimo de neutralidad. La utopía se sirve, además, de la imaginación para visualizar la reconciliación del individuo con la totalidad, de la felicidad con la razón. Ella es el ángulo visual desde el cual se ha de considerar el presente. La fidelidad a la utopía se explica entonces como un continuo ejercicio crítico a través del cual la realidad es proyectada hacia el futuro, para que coincida con la realización de la razón.

Marcuse advierte que la idea de una civilización no represiva no es utópica, sino perfectamente realizable, dado que existe ya la posibilidad de una transformación en el ámbito material que puede conducir a nuevas formas de vida. Por eso asegura que ha llegado el fin de la utopía (Marcuse [1967] 1968: 7). La utopía que ha finalizado es, pues, aquélla que se presuponía imposible. Marcuse distingue el concepto extra-histórico y el concepto histórico de utopía. Sólo el primero es utopía, en el sentido estricto de un ideal irrealizable. Existe en cambio, un concepto histórico de utopía. Una utopía que, aunque históricamente no se haya cumplido, puede encontrar en el futuro un lugar en el tiempo. Es u-topía ahora, pero es posible, aunque no verificable. La utopía se inicia dentro de lo real, pero más allá de su concreción. Es decir, los conceptos tienen que dejar de orientarse por la realidad fáctica y hacerlo por la virtualidad. Por eso las posibilidades llamadas «utópicas»son, en su opinión, la negación histórico-social determinada de lo existente. La eliminación de la utopía nos llevaría a reducirlo todo a problemas de hecho, a abandonar cualquier intento de configurar y comprender la historia; no puede, sin embargo, realizarse de una vez por todas sin dejar de ser utopía, y ello no porque sea irrealizable, sino precisamente porque considera lo imposible como una posibilidad. De ahí la necesidad de la utopía para forzar a la realidad a que aproveche todas las posibilidades que contiene.

El relativismo la abandona de la misma manera que renuncia a la búsqueda de la verdad y así no sólo se contradice afirmando desde un lugar absoluto que no hay verdad o sentido, sino que nos condena a la opacidad y al sinsentido de todas nuestras acciones. Nuestra convicción es que en la era global y multicultural sólo se llegará a una transmutación de la política y de las instituciones que la ciudadanía reclama con utopía. Cualquier proyecto de futuro debe contar con ella, de la misma manera que cuenta con lo sedimentado: como una lección del pasado que no ha pasado por completo. Si dicho proyecto es utópico, no lo es por ser mera literatura de ficción, sino por su capacidad para distinguir lo dado de lo que podría ser, para no identificar lo real con lo racional y no caer en el inmovilismo.

La concepción fenomenológica de la utopía de la razón, de ésta como telos de la humanidad, su interés por el sentido, por lo real-virtual, su concepción del pasado como retención del presente, es decir, como aprehensión voluntaria de lo que se considera valioso de éste y digno de ser reactivado, no están lejos 
de esta consideración crítica de la utopía como una verdadera estructura del pensar y del actuar, como orientación vital y hasta como tendencia utópica en el ser humano (Bloch).

\section{Del Multiculturalismo a la Interculturalidad}

Sólo en este sentido, como estructura de pensamiento crítico, la interculturalidad podría considerarse un proyecto utópico. No así el multiculturalismo; en los términos de Marcuse, sería preciso decir que ha llegado el final de la u-topía multicultural, porque se ha instalado en todas nuestras sociedades debido a las migraciones y a la globalización, pero ¿ha supuesto esto poner en práctica la interculturalidad? Abordaremos ésta de manera conceptual y ética para sentar las bases de su gestión sociopolítica. Esta última se ha convertido, en nuestros días de creciente reafirmación de las identidades, en una necesidad para vivir pacíficamente. Sin embargo, la interculturalidad no es sólo un medio para evitar los conflictos; ni siquiera es un fenómeno novedoso, ya que siempre ha formado parte de nuestro ser relacional.

Cada cultura es una interpretación de la realidad que es vivida desde diversas situaciones, pero la interculturalidad no sólo aporta elementos culturales a la descripción de la vida. Es una interacción compleja entre identidades pretendidas y diferencias cambiantes en la que confluyen los sentidos culturales y se legitima un encuentro entre sujetos capaz de articular sus relaciones. Éstas forman parte de cada sujeto que coexiste dando y recibiendo sentido. Consideramos que es preciso recuperar la subjetividad y, con ella, el interés crítico y emancipador. Estamos de acuerdo con Touraine, en la necesidad de reconocernos como sujetos para vivir juntos con nuestras diferencias en la era de la globalización económica, entendiendo que «sujeto» es la libre construcción de la vida personal, «el único principio universalista que no impone ninguna forma de organización social y prácticas culturales» (1997: 174).

Para la fenomenología, como para Hegel, el reconocimiento del otro se produce cuando se afirma como sujeto. El sujeto fenomenológico no se limita a reconstruirse discursivamente, ni a afirmar su carácter nómada desentendiéndose de las diferentes situaciones que nos determinan. Para los migrantes pobres, ser sujeto tiene que ver con buscar nuevas formas de pertenencia, porque aspiran a detentar derechos y capacidades para hacer frente a la violencia y a la crisis que se ceba en ellos. Estos desplazados gozan de la apertura multicultural de nuestra era globalizada, pero constatan el vacío de la misma, es decir, el hecho de que no va acompañada de estructuras y de leyes que garanticen la igualdad en la diversidad.

La interculturalidad no es, por tanto, un hecho, ni tampoco un valor emergente, sino un fenómeno irreducible al «todo vale». El relativismo que considera inconmensurables las diferencias poco puede aportarle. A lo sumo, describiría el multiculturalismo y éste corre el peligro de convertirse en una 
ideología, en una nueva jaula invisible que exime de razonar. Para evitarlo, hemos de abordarlo como interculturalidad, como tarea transdisciplinar de encarar el multiculturalismo como un proceso relacional en el que cada identidad se conforma gracias al intercambio con otras. Sin esta relación, sólo sería indiferencia ante las diferencias, una actitud pasiva que no abunda en el enriquecimiento cultural.

La fenomenología puede fomentar la interculturalidad, ya que se interesa por el sentido de las relaciones como tales y por los sujetos que las entablan. El punto de partida para que haya sentido es la no indiferencia; exige tener en cuenta a los otros como sujetos de relaciones que reflexionan y dan sentido a la interculturalidad viviendo en común. Así participan en ella fomentando narrativas convergentes; a su vez, la interculturalidad enriquece la capacidad de interaccionar de los sujetos.

\section{DE LA INTERSUBJETIVIDAD A LA INTERCULTURALIDAD}

Los sujetos, en sus relaciones con el mundo y con los otros generan las culturas y fundamentan la sociedad como intersubjetividad (Cf. López: 1994). Ésta es uno de los temas recurrentes de la fenomenología y Husserl reconoce su trascendentalidad, no sólo por estar constituida por egos trascendentales, sino por ser condición de una sociabilidad reflexiva.

Cada ser humano es una auto-objetivación del ego trascendental (Cf. Husserl: [1954] 1976: 190) porque constituye activamente dicha intersubjetividad. A su vez es constituido en ella mediante la modificación anagolizante con el otro ego. No puedo experimentar directamente su conciencia y esta es justamente la garantía de que siempre será otro que yo. Intersubjetividad trascendental es, por tanto, reconocimiento de los sujetos como realidades constituyentes y constituidas.

A diferencia de Hegel, la fenomenología no ve la intersubjetividad como lucha de conciencias, sino como comunización y conexión de nuestras experiencias con la intersubjetividad donadora de sentidos al mundo, incluido al yo humano mundano. Cada ego trascendental reactiva críticamente el sentido que se ha sedimentado históricamente, proyectándose en él desde su momento histórico y cultural. De este modo, se funda un sentido que es obra de la razón y permite reflexionar sobre el papel del sujeto como expresión de una cultura en relación con otras. De ahí que el reconocimiento del otro como otro ego trascendental sea esencial para pensar las relaciones humanas y comprender el diálogo intercultural como puesta en común de pretensiones racionales de coexistencia y comunicación. Esta última es otro estrato superior de constitución, correlativo al desvelamiento del yo como persona. Una persona es un ser relacional: un centro activo de apercepción y decisión en una "comunidad de mónadas» (Husserl 1973a:170-1), es decir, de egos trascendentales con sus 
mundos constituidos intersubjetivamente como diferentes modos de donación del mismo mundo.

A diferencia de las ciencias que estudian a los seres humanos como objetos de la naturaleza, Husserl se dirige a ellos "como personas, como sujetos de conciencia» ([1935] 1994: 162). Adopta la actitud personalista, radicalmente distinta de la naturalista, porque la vida es coexistencia personal; dirigirse a los otros seres y culturas es tener presente su vida intencional, comprenderlos por Einfühlung (empatía) y constituir el mundo intersubjetivamente.

La persona sustenta el hecho social. Cada una tiene un yo, pero otro. La fenomenología de la coexistencia se enfrenta a esta aparente paradoja comprendiendo que yo y otro no son positividades, sino intencionalidades que se entrecruzan sin agotarse jamás. Ver otro yo, no sólo significa proyectarnos en él para descubrir lo familiar, sino también comprender lo que parece semejante como propio del otro. Así, no sólo quedan preservadas las particularidades, sino asumidas en su irreductibilidad, como rendimientos de la intersubjetividad.

Frente a la comunidad hegeliana que se presenta como una «macropersona» de la que el individuo es sólo un momento abstracto, la intersubjetividad fenomenológica es constituida por sus miembros; sin embargo, no es una suma de egos, sino la estructura generadora del mundo de la vida que nos es predado como mundo cultural que adquiere su propio sentido en relación con otros. El mundo que nos resulta familiar ha sido sedimentado intersubjetivamente; remite al mundo extraño que lo delimita y es reconocido cuando entra en relación con el propio. Lo mismo ocurre con las culturas: "Las culturas y humanidades ajenas se hallan en un horizonte mediado: pertenecen a él en tanto ajenas y extrañas, pero la extrañeza significa accesibilidad en la propia inaccesibilidad, en el modo de la incomprensibilidad» (Husserl: 1973b, p. 631). Esto significa que el sentido de lo ajeno no se da asimilándolo a lo propio, sino de un modo indirecto, desde la propia otredad. Por su parte, la alteridad no es absoluta, ya que somos capaces de reconocerla. Análogamente, aprehendemos las otras culturas como semejantes y, a la vez, como diversas.

Así es como la trascendentalidad husserliana aborda la interculturalidad con radicalidad, subvirtiendo los dualismos: pensando lo familiar y lo extraño en su interrelación, porque necesitamos la alteridad para constituir la identidad y a la inversa. Esa interrelación se encuentra ya en cada comportamiento humano, que es siempre respuesta a otro (Cf. Husserl 1973b: 476). Pone de manifiesto que lo ajeno no es lo contrario de lo propio, sino su otra cara, la que se nos revela cuando nos interpelamos a nosotros mismos y a nuestra cultura.

En esta línea Merleau-Ponty ha desarrollado la intersubjetividad como coexistencia e intercorporeidad (Cf. López: 2001a y 2004). La experiencia de la intercorporeidad es de inmediato experiencia de intersubjetividad debido a la trasgresión intencional que, a través de la percepción del cuerpo del otro, me lleva a la totalidad de su persona sin necesitad de mediación intelectual. El sujeto que cumple dicha trasgresión sólo puede ser tal por ser situado; lo mismo ocurre con la experiencia de otro, cuya posibilidad arranca de la situación que forma parte del cogito. A diferencia del objeto, el otro es, como yo, un 
cuerpo-sujeto, una forma de comprometerse con la situación y de co-existir en un inter-mundo (Cf. Merleau-Ponty 1964: 322). Esta determinación mutua es la que lleva a Merleau-Ponty a negar que la verdad de una sociedad corresponda a la perspectiva del más desfavorecido (Cf. 2003: 161); esto no sería más que superponer otra subjetividad a la mía. De manera similar, la unidad sartreana inmediata del para-sí y del para-otro se le antoja mera alternancia, doble verdad; él busca la verdad del doble, es decir, que el yo sea otro y que el otro sea también yo. Para ello, hay que dejar de concebirlos como absolutos; ver a cada uno como estructura dialéctica entre interioridad y exterioridad, cuya dinámica define el campo de gravitación social. Este fenomenólogo afronta la subjetividad como un circuito integrado por el yo, el otro y el mundo, como una existencia. La razón surge en ella como «reactivación de una serie de operaciones culturales» reanimadas por nosotros en el "presente viviente» (Merleau-Ponty 1998a: 419). Lo instituido-instituyente es un universo vertical o carnal y su matriz polimorfa: «el mundo nos es común, es intermundo — hay transitividad por generalidad» (Id 1964: 323). La generalidad vivida posibilita la comunicación con otros y se desarrolla con ellos; nos permite comprender, más allá de las personas, los existenciales, que son el sentido sedimentado de todas nuestras experiencias, pero que no se encuentran en nuestro interior, sino ante nosotros, como la articulación de nuestro campo, como «Urgemeinschaftung de nuestra vida intencional» (Ib. 233-234). Ellos hacen que todas las culturas, como idealidades que son, proporcionen verdades sobre el mundo y orientaciones para la praxis.

La manifestación objetiva de la intersubjetividad son las Gestaltungen (configuraciones) sociales: estructuras sincrónicas y diacrónicas, sistemas integradores abiertos a las transformaciones y, en suma, procesos instituyentes de significado enraizados en el polimorfismo del ser, que es el fundamento ontológico de la diversidad y de la capacidad acumulativa (Cf. Id. 2003: 44). En esta ontología pluralista, el otro no es sólo la discrepancia a evitar, sino una invitación al encuentro con otras dimensiones del sí mismo y a la formación de verdaderas comunidades.

Según Merleau-Ponty, tan erróneo es absolutizar la razón como las diferencias culturales. Comprender al otro sin sacrificarlo a nuestra lógica o sin sacrificarla a él exigirá rehabilitar al sujeto encarnado, abierto intencionalmente a lo que le precede y excede, cuya raíz es la reciprocidad entre interioridad y exterioridad, entre cultura propia y ajena. La intencionalidad fenomenológica las conjuga, porque vive re-flexivamente la praxis de los sujetos, como intersubjetividad y ésta como un movimiento doble, centrífugo y centrípeto. Así les recuerda a las ciencias sociales que sólo desde la pertenencia a tradiciones podemos abrirnos a otras culturas.

Si las ciencias sociales necesitan construir modelos abstractos que reducen el dinamismo primordial, la fenomenología, es tan consciente de éste que no puede caracterizarse ni por su objeto ni por sus métodos, sino por su constante apelación a la inserción viviente en la intersubjetividad histórica. Toma 
conciencia de ésta como de un acontecer que enmarca la praxis del individuo en las relaciones sociales.

Las exploraciones fenomenológicas de la intersubjetividad se continúan en una filosofía intercultural si incorporan esta dialéctica, si hacen suyo el proyecto de una fenomenología de la razón ampliada, que no pierda de vista lo esencial para todo ser humano y que, al mismo tiempo, sea capaz de asumir las diferentes formas que puede tomar la aspiración a llevar una vida razonable.

\section{Hermenéutica de La inTerculturalidad y La tradición}

Cada yo es indeclinable, pero configura el nosotros que se forma como entretejimiento de alteridades recíprocas. Con esto queremos decir que el pluralismo forma parte del nosotros. De ahí que podamos ponernos en el lugar del otro, reconociendo la diversidad de la existencia humana y los lazos comunes que permiten darle significado.

Como la fenomenología, la hermenéutica reconoce al otro como constituyente de la intersubjetividad que culmina en el intercambio comunicativo. Este es verdadero si acepta que al otro se le puede dar la razón y que uno mismo puede no tenerla. Como la fenomenología, Gadamer capta la proximidad del otro en su otredad a fin de lograr una participación recíproca (Gadamer [1989] 1995: 33-4). Por ella se configuran las culturas, las cuales crean tradiciones cuando transmiten ${ }^{4}$ ideas y modos de actuar y de transferir lo aprendido. Cada cultura, cada individuo decide reactivar o no determinados componentes de las tradiciones y hacerlo de modo crítico y creativo o bien repetitivo. Sólo la primera decisión es consciente de su pertenencia y de su co-autoría de la tradición. La actitud fenomenológica se dirige hacia ella para averiguar cómo nos sigue hablando; la descubre como un movimiento doble que es otro para ser sí mismo, que necesita «olvidar para conservar, producir para recibir» (MerleauPonty 1998b: 37).

Cada tradición viva es configurada por los individuos; forma parte del saber generativo que debería conducirnos a reconocer el valor de verdad de las diversas potencias del instituir humano. Se nutren de la relación entre la presencia sedimentada de lo instituido y la latencia de las posibilidades de lo instituyente. Lo que diferencia a las tradiciones culturales de sus manifestaciones históricas es esa sedimentación que instituye su idealidad: las tradiciones no son series de hechos, sino efectuaciones de la conciencia humana intersubjetiva, de la libertad de sus respuestas a la historia sacando de ella lecciones y articulando los sentidos, distintos para cada cultura.

4 GADAMER denomina a la tradición «transmisión» (Überlieferung). Husserl va más allá: no todo lo transmitido forma parte de la tradición, sino únicamente lo que queda sedimentado y es conscientemente reactivado (Cf. LóPEz: 2012a). 
Según Merleau-Ponty, «el único modo de ser de la idealidad es la sedimentación» (1964: 288), entendida ésta como la cristalización de las relaciones en ciertos existenciarios que se actualizan en cada ser-en-el-mundo. Nos relacionamos con lo sedimentado abriéndonos a la idealización como telos de una tarea infinita (Cf. Merleau-Ponty 2003: 98) desde nuestra auto-comprensión y dialogando hasta conformar las bases de una tradición, entendida de manera prospectiva, no como una determinación que viene del pasado, aprendiendo a cuestionar y ampliar la propia cultura después de habernos acercado comprensivamente a la de los otros.

Cada sujeto imprime al mundo una deformación coherente mediante el estilo ${ }^{5}$ con el que reactiva la tradición, que nunca proporciona significaciones transparentes y esto es precisamente lo que la impulsa hacia otras tradiciones, que, por tanto, no son reificaciones; tienen que ser construidas y reconstruidas por cada integrante; se nutren de la relación entre la presencia sedimentada de lo instituido y la latencia de las posibilidades de lo instituyente.

La tradición no nos determina; abre nuestros horizontes, amplía nuestra capacidad de escucha. Hay que interpretarla como configuración de la finitud que permite que la trascendamos, como tarea siempre inacabada de la comprehensión y la comunicación que son el logos del mundo intersubjetivo e intercultural: cuando tomo conciencia de que lo que digo tiene un sentido sedimentado, soy otra y cuando comprendo, algo ajeno pasa a formar parte de mí. La comprensión de lo ajeno no es un acto cognitivo, sino político y moral; de ahí que comprender al otro sea siempre una interpretación y una aplicación a un mundo en el que no sólo hay enfrentamientos comunicativos, sino también reales. Idéntico alcance tiene, para nosotros, el diálogo.

\section{Diálogo intercultural}

Nuestra capacidad de desdoblamiento nos permite habitar el mundo con otros, captar nuestra pluralidad y configurar el nosotros. Cuando el reconocimiento de la diversidad de la existencia humana y los lazos comunes que la significan se reafirma dialogando, se pasa de una sociabilidad pasiva a otra eminentemente activa.

El diálogo no es un modo del discurso, sino una exigencia de nuestra humanidad, que es logos e interculturalidad; no vale per se, sino como la voluntad de abrirse al otro desde la situación concreta de cada interlocutor (Cf. Gadamer [1989] 1995: 59), alcanzando la fusión de horizontes entre lo propio y lo ajeno.

5 El «estilo» es nuestra relación original con el mundo (Cf. Merleau-Ponty, M. 1969: 79). Husserl considera al yo como sustrato de habitualidades y «estilo constante, con una ininterrumpida unidad de identidad, un carácter personal» ([1931]. (1991): 101). Nosotros concebimos el estilo como configuración progresiva de la identidad articulando las diferencias (Cf. LóPEz 2008: 54-57). 
Su objetivo no es la negociación, ni el consenso, sino el entendimiento sobre die Sache (la cosa), que, es el tema que nos ocupa.

Para que este diálogo sea intercultural es preciso que se den una serie de condiciones $^{6}$ que permitan pasar de la facticidad multicultural al proyecto de vida común y pacífico ${ }^{7}$. Este diálogo intercultural no se produce en un marco de relaciones de dominio, sino reconociendo a los otros como interlocutores, aprendiendo a no tener razón, renunciando a la verdad absoluta y saliendo de él transformados. No basta respetar y dejarse cuestionar por las otras culturas, sino que es necesario responder. Esto es «la cultura como responsabilidad por el otro» (Lévinas 1991: 206). La constatación de las diferencias no puede llevar a la mera indiferencia frente a todo lo otro, sino a una mayor responsabilidad ante «la proximidad del prójimo» (Ib. 207).

El diálogo intercultural no consiste en hablar por hablar, sino en intercambiar experiencias y actitudes para llegar a un núcleo ético común. Como la fenomenología en la que se ha formado la hermenéutica, Gadamer insiste en lo común, en las experiencias implicadas en el lenguaje, pero también en los proyectos conjuntos.

El sentido fenomenológico no se reduce a los significados culturales; se prolonga en los valores morales y éstos no vienen dados por la cultura, sino que permiten juzgarla. Ciertamente, el único criterio válido para ello es el de su contribución a una vida más humana guiada por la razón común: «asegurarán, a la vez, la mayor autonomía y autenticidad en la vida comunitaria, pero no conservar oscuras "identidades" nacionales, ni tampoco aceptar una "universalidad" de hecho que podría ocultar una forma nueva de irracionalidad» (Villoro 1993:154). Una cultura no es razón suficiente para consentir el sufrimiento humano. De ahí que la interculturalidad deba evaluar los efectos de las culturas sobre las personas y reconocer sus derechos y sus deseos.

El diálogo entre culturas requiere respeto hacia ellas y hacia sus integrantes, pero también una determinada concepción del mismo. La nuestra es una extensión del diálogo que somos y que no vale per se, sino como la voluntad de abrirse al otro desde la situación concreta de cada interlocutor, sin perder el propio ser (Cf. Gadamer [1989] 1995: 59), alcanzando la fusión de horizontes entre pasado y presente, lo propio y lo ajeno. Las experiencias propias no se sintetizan por la apropiación de las ajenas, sino que se corrigen y se desapropian. Esta "fusión» de horizontes no es, por tanto, confusión, sino preservación de las dimensiones en las que podemos participar sin renunciar a lo que sigamos considerando válido de nuestra propia cultura.

Gracias al diálogo desaparece la aculturación y se inicia un proceso de interculturalidad en el que «tolerancia» no significa renunciar a lo más propio, sino escuchar e intercambiar razones mientras se experimenta la intersubjetividad

6 Habermas es uno de los autores que más ha insistido en las condiciones trascendentales del diálogo (HaBermas, 1992). Nosotros nos conformamos con los principios de respeto, igualdad y veracidad.

7 G. GonzÁLEZ, se refiere incluso a una «cultura de la paz» (GonZález 2008: 209ss). 
comunicativa que preside la vida empírica y en la que vamos construyendo nuestra identidad en la diversidad. Esta dinámica intra-cultural es la que permite la interculturalidad y determina que la identidad cultural radique en su carácter dialogante, el cual define una identidad procesual que se conforma en interacción con las diferencias.

\section{CONFIGURACIÓN DE LA IDENTIDAD EN LAS DIFERENCIAS}

La interculturalidad no permanece, como dijimos, indiferente ante las diferencias, sino que se responsabiliza por el otro y pone en cuestión la identidad. Toma conciencia de que no hay identidad pura, sino configurándose en múltiples situaciones (género, clase social, etnia, nación). No es sólo una realización individual, sino también una construcción socio-cultural. La exacerbación de la identidad puede llevar al fundamentalismo particularista. Para evitarlo, hay que comprenderla en el contexto de las diferencias que van siendo asumidas y redefinidas, con diferentes voces. Identidades y diferencias interactúan gracias a la interculturalidad.

Por tanto, lo importante no es la identidad que se cree acabada, sino el proceso relacional ininterrumpido por el que atraviesa. Se perfecciona a través del reconocimiento de lo diverso, pero sin sucumbir ni al exotismo, ni a la subordinación al valor impersonal del mercado. La creciente diversidad cultural obedece en gran parte al mercado global y puede ser conflictiva por las desigualdades que genera, que también afectan a la pluralidad intra-cultural e individual. Es necesario sospechar de este exotismo y aceptar las diferencias culturales en la medida en que contribuyan a la integridad de las personas. La fenomenología intercultural puede ayudarnos a sopesarlas. Su estudio de la intersubjetividad nos ofrece un modelo apto para la relación entre culturas: la autorrealización del ser humano supone el carácter intersubjetivo de nuestra existencia y la comunicación con los otros, pero, a la vez, la intersubjetividad requiere una clara conciencia de la propia y distinta subjetividad. De manera análoga, la interculturalidad es un proceso relacional en el que las identidades buscadas se gestan en las diferencias: «La trascendencia es identidad en la diferencia» (Merleau-Ponty 1964: 279); nos impulsa a superar la inmanencia, pero también a comprender que sólo desde ésta se abre su posibilidad. Esta fórmula rechaza la absolutización de la diversidad tanto como la de la identidad, pues lo único real es que ambas toman forma en sus interacciones, como continuidades en el seno de las discontinuidades histórico-sociales.

Si la identidad coexiste con las diferencias, también la igualdad puede convivir con las que no sean discriminatorias, pero «igualdad» no significa ni uniformidad ni identidad cultural; como la interculturalidad es un concepto normativo. Por ello, la interculturalidad debe trabajar por una igualdad compleja que recoja las diferencias legítimas. Ha de adherirse a una nueva ontología no dualista, si quiere ir más allá de un eclecticismo cultural neutro o de un 
puro exotismo que deja como está las relaciones de dominación y las desigualdades que originan.

Identidades y diferencias no son realidades acabadas. La identidad cultural sólo es una dimensión de la compleja identidad humana y, como hemos visto, se desarrolla en la interculturalidad. Por su parte, la cultura es diacrítica, reveladora de una única sintaxis diferencial: «Todos los gestos que hacen que una cultura exista tienen afinidad entre ellos, en tanto momentos de una única tarea, pero no pueden suplirse, sino que se exigen unos a otros en su diferencia puesto que ninguno puede ser idéntico a otro a no ser que se ignoren entre sí» (Merleau-Ponty 1960: 113). Este pensador aseguró que las semejanzas son poca cosa en relación con la innumerable variedad de culturas (1969:111).

Lévi-Strauss fundó el valor de la diversidad cultural en este carácter diacrítico ${ }^{8}$; Sin embargo, afirmar la inconmensuralidad de las diferencias es caer en la contradicción performativa y no fomentar la interculturalidad. El verdadero problema no es exaltar la diversidad o buscar una cultura originaria para subordinar las otras a ella, sino comprender por qué culturas tan diversas emprenden tareas análogas, persiguen fines comunes ${ }^{9}$ y por qué lo que produce una cultura tiene siempre un sentido para las otras.

Esta interrogación está en el origen de la interculturalidad; no surge de manera espontánea, sino que es preciso educarse en ella.

\section{Formarse EN LA INTERCULTURALIDAD}

El paso del multiculturalismo a la interculturalidad, necesita educación. La escuela no es, sin embargo, su panacea; su misión no es ni reproducir las discriminaciones ni aparcar los problemas sociales, pero tampoco educar en la cultura dominante.

Como Gadamer, entendemos la educación como formación (Bildung) del juicio y de la manera humana de ser mediante la Aufhebung (elevación) de la particularidad a la universalidad sin subsumirla en un saber superior. Entendida así, la formación proporciona un saber que interviene en la situación a la que pertenece, principalmente un saber de los límites que nos abre a la alteridad, una praxis y una comprensión de la verdad de las otras culturas (Cf. Gadamer [1960] 1986: 22).

Como la «distancia en la proximidad» (Merleau-Ponty 1964: 187) entre lo propio y lo ajeno, que da cuenta de un mundo común, la Bildung no objetiviza; no es una techné, sino un querer lo que se puede y lo que no se puede hacer en

8 LÉvi-STRauss fundó el valor de la diversidad cultural en su carácter diacrítico. Sobre los riesgos de su relativismo y su posible corrección mediante la fenomenología de la existencia, véase López: 2012b: 91-104.

9 Esta orientación común es justamente lo que les permite reconocerse como diferentes. Como dice Merleau-Ponty, «las culturas se relacionan, porque se necesitan unas a otras en su diferencia y sólo parecen idénticas cuando se ignoran entre sí» (1969:113). 
función de la conciencia social que toma decisiones que afectan a la humanidad. Ésta es un universal inminente que se gana ampliando nuestro horizonte, cuestionando nuestras certezas y respondiendo de los otros.

La cultura ética de la responsabilidad por el otro tiene, en Lévinas, un sentido análogo, porque no consiste en que lo Mismo del Yo humano se confirme en su identidad absorbiendo lo otro, sino en cuestionar esa presunta identidad (Cf. Lévinas 1991: 207). Esto es lo que determina la capacidad para la interculturalidad y lo que tanto se echa en falta en nuestros días en los que prima el absolutismo de la propia opinión sin contrastarla.

Desde la perspectiva fenomenológica, la universalidad en curso, orientada hacia la humanización por la racionalidad, es la base del mundo de la vida intercultural y, en relación con él, es posible tematizar la educación. Su telos se actualiza en cada ser humano y posibilita una ética intercultural cuyo núcleo común son los valores democráticos y la revisión de cada cultura de acuerdo con «un principio universalista de justicia» (Pérez 2007: 169) al que apuntan todas.

La Bildung no es ni el punto de vista del otro ni el mío, sino el de cada descentramiento del mundo al que se pertenece; por eso es una concreción de un universal inminente. Coincide con la universalidad misma de la humanidad, la cual se gana ampliando horizontes desde la particularidad de cada cultura, el cuestionamiento de las propias certezas, el reconocimiento de lo común en la otredad — propia y ajena - como base de la progresiva creación de solidaridad. Esta última viene posibilitada gracias a uno de esos contextos relacionales en los que los interlocutores interpretan el mundo, gracias a la interculturalidad (Gadamer [1986] 1990: 185). La solidaridad sustituye a la tradición en los últimos escritos de Gadamer. Es previa al diálogo, no uno de sus resultados. Gadamer, como la fenomenología, ha subrayado la necesidad de elevar a la conciencia lo que nos une, de reflexionar sobre las solidaridades de la vida humana:

Me parece un defecto de nuestra mentalidad pública que siempre destaquemos lo diferente, lo discutido, lo polémico y desesperado de la conciencia humana y que dejemos, por así decirlo, sin voz, a lo verdaderamente común y vinculante. Ya hemos cosechado los frutos de una larga educación para lo diferente y la sensibilidad que exige la percepción de las distinciones (Gadamer, [1989] (1995):156-157).

La solidaridad se hace efectiva ${ }^{10}$ profundizando en cada cultura y proyectándola hacia fuera, dinamizándola intra-cultural e interculturalmente. Para ello, es necesaria la crítica de la cultura dominante desde una cultura de la otredad, pero sólo comprendemos una cultura como otra participando en ella. Esta dialéctica entre distanciamiento y participación aspira a una comprehensión que abra nuevas posibilidades para la auto-comprensión y la intersubjetividad.

10 Para que esta solidaridad se extienda a las víctimas de injusticias, la hermenéutica gadameriana de la participación debería complementarse con la hermenéutica crítica. 
Nosotros partimos de ellas, porque vinculamos la relación entre culturas con el respeto hacia los otros y hacia nosotros mismos, con la tendencia a una racionalización que nos haga más humanos y, sobre esta base, más interculturales.

\section{INTERCULTURALIDAD COMO UNIVERSALIDAD CONCRETA}

Humanización y racionalización aportan el telos de universalidad que conviene a la interculturalidad; no se trata de una universalidad que hace abstracción de las personas, sino de la universalidad concreta (Cf. López 2012: 77ss), que expresa el sentido de nuestra humanidad en cada existencia y en cada cultura. Llegamos a ella de manera indirecta, desde cada sujeto que se descentra para interaccionar. Esta universalidad es virtual, porque «el paso de lo particular a lo universal nunca está concluido» (Merleau-Ponty 2003: 97); no elimina lo individual, sino que ve en él su génesis ininterrumpida. No es potestad de una cultura concreta, sino que está presente en todas, pero trascendiéndolas hacia las demás, porque todas tienen logos y mythos y ejercen una función simbólica, que no sólo es fuente de razón, sino que «se adelanta a lo real en lo imaginario (...) La tarea es, pues, ampliar nuestra razón, para hacerla capaz de comprender lo que en nosotros y en los otros la precede y la excede» (Id. 1969: 154).

Esta razón de la que germina la nueva universalidad es comprehensiva, ya que no sólo se abre a la experiencia de lo extraño, sino a todo lo que es fundamental para la revisión de lo propio: a la experiencia, a la afectividad, a la sensibilidad. Si la etnología asume este telos, cesará de definirse por su «objeto» de estudio y pasará a caracterizarse por su modo de pensar al otro transformándonos hasta convertirnos en etnólogos de nosotros mismos, aprendiendo a ver lo propio como extraño y lo ajeno como una de nuestras posibilidades. La interculturalidad pierde, entonces su carácter unidireccional y la fenomenología se reafirma como conciencia de la racionalidad en la contingencia.

No es una solución oponer al universalismo economicista el multiculturalismo relativista. Hay que pensar otros modos de reconocimiento de lo compartido en las diferentes vivencias. Para alcanzar dicho reconocimiento, es preciso criticar el modelo ideológico que cuantifica la diversidad existencial, unidimensionaliza la razón y reduce la intencionalidad a la maximización del beneficio: «Cada grupo humano, porque es humano, tiene el derecho al respeto y la integridad, pero no cada una de sus normas o sus prácticas. La beatería de la diferencia no debe disuadirnos de la conquista de la universalidad» (Valcárcel 2002: 20).

Consideramos que la universalidad existencial contribuye a ello; su investigación de lo común soslaya el culturalismo abogando por un saber que no se limita a acumular conocimientos de las diversas culturas, pero se deja enseñar por alguna de ellas para recuperar la propia «región salvaje» (Merleau-Ponty 1969: 151) por la que comunica con otras. Ahora bien, como nos recuerda 
Lévinas, esa apertura no es infinita, porque «la cultura es irrupción de lo humano en la «barbarie del ser» (1991: 207).

En la diversidad cultural no encontramos la unidad de la razón, sino una serie de procesos de racionalización que interpretan culturalmente la racionalidad. No obstante, para evitar la reducción culturalista, la fenomenología reenvía en última instancia a la unidad del horizonte del mundo, de la racionalidad que se halla anclada en él y en la cultura como su aspecto auto-interpretativo.

Como el sujeto relacional, como la intersubjetividad, la interculturalidad es una tarea en un contexto cada vez más plural. La fenomenología no sólo se abre a ella describiéndola como intersección e interpretación de modos diferenciados de ser y sentir, sino que apunta a la interculturalidad como telos de una razón humanizadora que se va corrigiendo interculturalmente y exponiéndose en lo otro. Es consciente de que la pluralidad es un hecho que nos rebasa, pero también de que es posible tender a una universalidad concreta que permite acceder a otras culturas aprehendiéndolas primero como diferentes y concibiendo entonces la propia como una variante.

La búsqueda de esta universalidad no nos aboca al relativismo radical, porque es posible hallar ciertas estructuras que no sólo no anulan las particularidades, sino que necesitan secuenciar lo sedimentado en cada singularidad. La universalidad existencial a la que nos referimos nos recuerda que toda generalidad requiere una interpretación que la aplique a lo diverso y la plasme así en generalidades concretas intersubjetivamente válidas. La conciencia de esta generalidad debería conducirnos a reconocer el valor de verdad de las diversas potencias y posibilidades del instituir humano, en lugar de abocar al relativismo cultural. Éste, ejemplificado en la máxima de Lévi-Strauss («un salvaje es el que llama a otro "salvaje"»), en aras de la diversidad, impediría denunciar a criminales reales que trataron como objetos a millones de seres humanos. El respeto a las diferencias culturales que invoca este relativismo olvida a las personas de carne y hueso, sus experiencias vividas que no son reducibles al discurso, ni pueden ser silenciadas.

La fenomenología de la razón puede ayudarnos a salir del laberinto del relativismo y del poder omnímodo del discurso, enseñándonos a profundizar en la experiencia vivida, a ser críticos y autocríticos de las tradiciones, a descubrir sentidos y a perseguir una universalidad que vamos adquiriendo profundizando en lo concreto.

Algo similar ocurre con cada lengua, que es una figura de la lingüisticidad. Ésta es universalizable, porque es «el lenguaje de la razón» (Gadamer [1986] 1990: 451) y el mayor poder de ésta es el entendimiento mutuo. Su universalidad no está en acto, es virtual, como el sentido mismo, porque existe recogiendo y trascendiendo lo particular. Gadamer, como Merleau-Ponty, investiga cómo actúa en medio de la diversidad lingüística la unidad de pensar y hablar.

Hemos visto que en coherencia con el telos husserliano de la universalidad de la razón que cobra realidad en cada ser humano, proclama la ampliación de la razón. En su fenomenología relacional podemos encontrar, además, una ética de la reciprocidad transversal que encuentra la alteridad en la ipseidad, y 
también a la inversa. De ahí que algunos autores hayan visto en su obra una base para la política democrática y para la praxis igualitaria (Cf. Madison 2001: 174) o una política para quienes experimentan la contingencia (Cf. Finn 1992: 171). El carácter relacional e intencional de la fenomenología proporciona sentido a dicha contingencia en la comunicación cultural, la integración social y la crítica de la fragmentación del mundo falsamente globalizado en la cultura de masas, fruto de la imposición del mercado. Si la interculturalidad se reduce a los dictados de éste, el sujeto se aliena, desparece la intersubjetividad y la diversidad cultural queda convertida en mero espectáculo. Para evitarlo, es preciso interaccionar con la diversidad buscando procesos de racionalización que interpreten culturalmente la racionalidad y remitiéndolos a la reordenación de la razón. Por eso es por lo que reivindicamos la interculturalidad sin reduccionismos, como una dinámica de emancipación y diálogo con el otro. Como ha dicho Touraine:

Sin el reconocimiento de la diversidad de las culturas, la idea de reordenación del mundo correría el riesgo de caer en la trampa de un nuevo universalismo y zozobrar en el sueño de la transparencia. Pero sin esa búsqueda de una reordenación del mundo, la diversidad cultural no puede llevar más que a la guerra de las culturas (Touraine 1997: 247-8).

Reformulando la cita, podríamos decir que la diversidad que experimentamos necesita ser reconducida reflexivamente para adquirir significado y, al mismo tiempo, la universalidad conceptual resulta vacía si no asume las particularidades. De ahí la utilidad del universal existencial.

La fenomenología propone, además, la reinterpretación y ampliación cultural que cada individuo puede realizar desde su identidad, su cultura, su situación y su apertura al otro, pero también la búsqueda social y política de interacciones paritarias. Desde esta fenomenología continuada, pensamos que es preciso criticar el universalismo económico que borra los sentidos y reduce los valores al consumo impuesto por una cultura, introyectado por las masas y, finalmente, mundializado por las nuevas tecnologías. Es necesario desenmascarar el modelo ideológico que cuantifica la diversidad existencial, unidimensionaliza la razón y reduce la intencionalidad a la maximización del beneficio. Sin embargo, no es solución oponerle el relativismo cultural. En nuestra opinión, la fenomenología intercultural permite trascender este hiato gracias a su interés por el sentido y a su investigación de lo compartido en las diferentes vivencias.

\section{Fenomenología de los derechos humanos}

Una interculturalidad equilibrada entre identidades y diferencias ha de tener como marco los derechos humanos, porque el valor de las personas es previo a la interculturalidad; no se puede defender sin tener en cuenta los derechos fundamentales y su adecuación a las diversas situaciones. La necesidad 
de reconocimiento entre personas «no significa igualar formas de vida diversas culturalmente, sino universalizar los derechos subjetivos respetando las diferencias» (Habermas 1996:74).

Se ha hablado incluso de una «emergente cultura de los derechos humanos» plasmada en las diferentes tradiciones y de la que puede germinar una «civilización intercultural» (Pérez 2007: 181). Sin entrar a debatir la distinción entre civilización y cultura, sí queremos recordar que estos derechos adolecen de formalidad y carecen de concreción. Para que no sólo sean los derechos de una minoría privilegiada, han de tener eficacia en todas las culturas y eso requiere que sean interpretados por ellas. De este modo, no sólo se percibirán como resultado del diálogo, sino que ganarán contenidos vinculados a los valores de lo humano: el potencial crítico y ético de la racionalidad, la dignidad y la libertad. Según Lévinas, esta última «marca la identidad absoluta de la persona, es decir, de lo no intercambiable, de lo incomparable y único. Unicidad, más allá de la individualidad de los individuos múltiples en su género» (Lévinas 1987: 160). Los modos diversos de esa libertad se concretan en los derechos humanos que son universales, porque se refieren al ser capaz de logos y de dia-logos, ser capaz «de ser no-in-diferente al otro. No-in-diferencia o socialidad-bondad original» (Ib.: 168). La socialidad es relación ética con lo absolutamente Otro, mientras que la racionalidad tiene alcance moral, ya que es encuentro con otros de los que se ha de responder. Siguiendo a Lévinas, los derechos humanos son deberes con respecto al otro que interpela a mi responsabilidad.

El formalismo no ha desparecido. Creemos que un modo de evitarlo es combinar su universalidad con la frónesis, la racionalidad práctica aristotélica - hermenéuticamente apropiada-, cuya meta no está determinada por lo que es justo en general, sino por lo que es bueno en determinada situación. Esta racionalidad responsable que orienta en cada caso particular se aproxima al universal concreto del encuentro indirecto entre culturas (Cf. López 2012: 77ss).

La propuesta de resignificación de las prácticas culturales a través de identificaciones narrativas que medien entre la universalidad de los discursos morales y los discursos éticos de la vida buena (Cfr. Benhabib 2002: 13) va en esta línea. Promueve un universalismo interactivo y concretiza al otro.

\section{Conclusiones}

Comprender el multiculturalismo como interculturalidad es dialogar en su contexto e ir configurándola como interrogación crítica y construcción de espacios de inteligibilidad para las diversas formas de alteridad.

La interculturalidad no es la aceptación pasiva del hecho de la multiculturalidad, ni un deseo bondadoso de armonización; tampoco es el remedio al choque entre civilizaciones, ni el nuevo problema que dejará de serlo cuando se eduque a los individuos en ella. 
Desde nuestra perspectiva fenomenológica, la interculturalidad es una de las dimensiones que constituyen al ser humano y revierte en la actitud reflexiva; ésta es intercultural en la medida en que pone entre paréntesis la actitud naturalista con objeto de interrogarse de un modo personalista por las relaciones entre culturas. Desde esta actitud fenomenológica, se afirma el valor de las personas y sus derechos; el multiculturalismo deja de ser una fragmentación ilimitada o una difusión masiva de bienes y vale la pena afirmarlo como interrelación que ayuda a cada ser humano a dilatar y a hacer más creadora su existencia.

Las reflexiones fenomenológicas explícitas sobre la intersubjetividad, la noindiferencia ante los diferentes, la responsabilidad que da significado al individuo, hayan su continuación en una filosofía intercultural, acorde con nuestros tiempos, si incorporan la dialéctica de lo propio y lo ajeno, practican el descentramiento y hacen suyo el proyecto de una razón ampliada a las diferentes formas que puede tomar la aspiración a vivir de un modo razonable. Una filosofía intercultural ha de insertarse en el proyecto de una fenomenología de la razón élargie que complemente el análisis objetivo con el de la experiencia vivida. Lo que proponemos no es una nueva versión de la philosophia perennis o de la religión, sino la interculturalidad de esta racionalidad englobante y no la de la racionalidad instrumental globalizadora. La fenomenología intercultural alienta un cambio del paradigma de la razón dominante hacia la racionalidad que existe en las pretensiones humanas de argumentar sobre sus valores y decisiones; da cuenta de esa razón intersubjetiva antes que discursiva, relacional y respetuosa de lo otro. Estos rasgos no la convierten en una razón indiferente o puramente teórica, sino en una razón que se va haciendo en la vida teóricopráctica, junto a la crítica de lo fáctico y a la interacción.

La referencia del universal lateral con el que caracterizamos la interculturalidad que se plasma en cada estilo de existir es la intersubjetividad vivida desde nuestro aquí y ahora; esta intersubjetividad encarnada nos capacita también para comprender la interculturalidad que atraviesa nuestra cultura, porque «Vivimos en la unidad de una sola vida todos los sistemas de los que se compone nuestra cultura» (Merleau-Ponty 1960: 150), recibiendo y reactivando determinados sentidos de otras culturas, en virtud de las variaciones imaginativas en torno a la nuestra, y al reconocimiento de sus límites, que permiten trascenderla: «Toda evocación del mundo posible remite a la visión del nuestro (Welt-anschauung). Toda posibilidad es variante de nuestra realidad, es posibilidad de realidad efectiva» (Ib.: 227-8). Las variaciones sobre un tema sólo existen simultáneamente a él y como pluralidad de vivencias.

Con estas consideraciones, esperamos haber mostrado que la fenomenología es una buena referencia para afrontar el problema de la diversidad de tradiciones y culturas sin recaer ni en el relativismo ni en el dogmatismo. Nuestra adhesión al proyecto merleau-pontiano de ampliar la racionalidad se ha manifestado como esbozo de un concepto positivo de interculturalidad, que no se agota en la yuxtaposición de mónadas, sino que se basa en la intercorporeidad y en la comunicación que se gesta ya en ésta como intercambio. Aunque no 
seamos conscientes de ello, todos practicamos más de una cultura y las divisiones culturales se entrecruzan para formar «modelos» sometidos a cambios constantes. De manera que si hay una esencia de la identidad cultural sólo puede radicar en su carácter dialogante con las demás y en su capacidad de autocrítica.

Algunos autores han considerado perniciosos e incluso reaccionarios los efectos del multiculturalismo ${ }^{11}$ que valora todas las culturas como intrínsecamente buenas. Para evitarlos, es preciso reflexionar interculturalmente y esto significa que la verdadera interacción cultural ha de ser dialógica y crítica de sí y de las otras culturas.

La interculturalidad, a diferencia del multiculturalismo, tiene carga ética. Ayuda, justamente, a ver lo propio desde parámetros ajenos y, a la inversa, a comprender las otras culturas desde lo que la propia pueda tener de generalizable. Ni todas las culturas occidentales son dominadoras y transgreden los derechos de las personas, ni todas las otras son valiosas per se. No hay que defender por exotismo las diferencias culturales, sino en la medida en que contribuyan a la integridad de las personas y denunciando los abusos que se producen cuando no se tienen en cuenta los derechos de los individuos, de las mujeres, de los niños y, en general, de los más vulnerables.

Las prácticas culturales y los comportamientos no siempre son acordes, por otra parte, con las culturas en las que se inscriben. A la fenomenología compete describirlas valorando su donación de sentido. Además, nos recuerda que los individuos no pertenecen a una cultura sólo por hallarse en un territorio o haberse imbuido de ella, sino, sobre todo, por reactivar su sentido críticamente y desde su situación, que incluye la posición social.

No es vano, por tanto, desarrollar la fenomenología intercultural en la línea de la utopía de la teleología de la razón, ya que la utopía es uno de esos fenómenos en los que el sentido (en su doble acepción de significado y orientación) no se manifiesta de una vez por todas. Lo mismo ocurre con el acceso al otro, que es lo que define, según Merleau-Ponty, a la sociología (1960: 144). La actitud fenomenológica ante estos fenómenos desconecta su carácter fáctico con objeto de descubrir su sentido, que siempre está más allá de lo dado. Permite así idear un futuro con visos utópicos y no una mera reduplicación de lo que hay.

El diálogo intercultural dista mucho de ser una ideología enmascaradora; tampoco es una u-topía, pues el multiculturalismo y el mestizaje forman parte de nuestra topología. Se trata de una tarea ética y política. Para llevarla a cabo, hay que huir de los absolutismos y de los indiferentismos, practicar el reconocimiento de las pretensiones de validez de las diversas tradiciones, el derecho a disenso de cada individuo y la plural participación en la búsqueda de una verdad que no podemos renunciar a hacer en común.

11 Cf. CoRTÉs 2010: 31. 
BiBLIOGRAFÍA

Benhabid, S. (2002) The Claims of Culture. Equality and Diversity in the Global Era. Oxford: Princeton University Press.

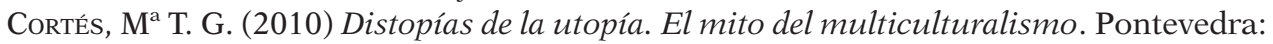
Ed. Académica del hispanismo.

GadAmer, H-G. [1960] (1986) Gesammelte Werke 1. Hermeneutik I. Wahrheit und Methode. Grundzüge einer philosophischen hermeneutik, Tübingen: Mohr.

- [1986] (1990) Gesammelte Werke 2. Hemeneutik II. Wahrheit und Methode. Ergänzungen. Register,Tübingen: Mohr.

- [1989] (1995) Das Erbe Europas, Frankfurt am Main: Suhrkamp Verlag.

Habermas, J. (1992) Faktizität und Geltung: Beiträge zur Discurstheorie des Rechts und des demokratischen Rechtsstaats, Frankfurt am Main: Suhrkamp Verlag.

- (1985) «El fin de una utopía», El País, 9-12.

- (1996) Die Einbezihung des Anderen: Studien zur politischen Theorie. Frankfurt: Suhrkamp.

Husserl, E. [1931] (1991) Cartesianische Meditationen und Pariser Vorträge. Husserliana I. The Hague: M. Nijhoff.

- [1935] (1994) «Husserl an Lévy-Bruhl 11.III.1935 (Durchschlag)», in Briefwechsel. Husserliana Dokumente III. Teil VII. Dordrecht: Kluwer, 1994, pp. 161-164.

- (1973a) Zur Phänomenologie der Intersubjektivität I. 1905-1920, Husserliana XIII. The Hague: M. Nijhoff.

- (1973b) Zur Phänomenologie der Intersubjetivität III. 1929-1935, Husserliana XV. Den Haag: M. Nijhoff.

- [1954] (1976) Die Krisis der europäischen Wissenschaften und die transzendentale Phänomenologie, Husserliana VI. Den Haag: Martinus Nijhoff.

LÉVINAs, E. (1987) Hors sujet, Paris: Fata Morgana.

- (1991) Entre nous. Essais sur le pensaer-à-l'autre. Paris: Grasset.

LóPEZ, M ${ }^{a}$ C. (1994). Investigaciones Fenomenológicas sobre el origen del mundo social, Servicio de Publicaciones de la Universidad de Zaragoza.

- (2000) «The child, the school and philosophy; a phenomenological reflection», Thinking. The Journal of Philosophy for Children, 15, 2, 34-40.

- (2001a) «Subjetividad transcendental como intersubjetividad en Husserl», Pensamiento, 57, 218, 251-273.

- (2004) «Intersubjetividad como intercorporeidad», La lámpara de Diógenes, 5, 57-71.

- (2008) «De la expresividad al habla. Un modelo diacrítico de interculturalidad», in López, Ma C., Penas, B. Paradojas de la interculturalidad. Madrid: Biblioteca Nueva, 31-57.

- (2012a) «Sédimentation du sens et Tradition (Überlieferung). Phénoménologie et herméneutique philosophique», Hermeneia. Journal of Hermeneutics, Art Theory and Criticism, 12, 39-62. Available http://hermeneia.ro/

- (2012b) «Universalidad existencial (M. Merleau-Ponty) frente a relativismo cultural (C. Lévi-Strauss)», in LóPez, M ${ }^{\mathrm{a}}$ C., DíAz, J. M. (eds) Racionalidad y relativismo. En el laberinto de la diversidad. Madrid: Biblioteca Nueva, 19-108.

- (2912c) Corrientes actuales de Filosofía I. En-clave fenomenológica. Madrid: Dykinson.

- (forthcoming) «Actitud reflexiva y educación. Aportaciones fenomenológicas-hermenéuticas», Revista Conceptos. 
Marcuse, H (1967) Das Ende der Utopie. Trad. Cast. El final de la utopía. Barcelona, Ariel, 1968.

Merleau-Ponty, M. (1960) Signes. Paris: Gallimard.

- (1964) Le Visible et l'Invisible. Paris: Gallimard.

- (1969) La Prose du Monde. Paris: Gallimard.

- (1998a) «Les sciences de l’homme et la phénoménologie», in Merleau-Ponty à la Sorbonne. Résumés de Cours 1949-1952. Paris: Cynara, 397-464.

- (1998b) Notes de Cours sur L'origine de la géométrie de Husserl. Paris: PUF.

- (2003) L'institution. La passivité. Notes de tours au Collège de France (1954-1955). Paris: Belin.

Penas, B., López, Ma C. (dirs) (2006) Interculturalism. Between Identity and Diversity. Nueva York/Berna: Peter Lang.

Pérez Tapias, J.A. (2007) Del bienestar a la justicia. Aportaciones para una ciudadanía intercultural. Madrid: Trotta.

Perlini, T (1976) La Escuela de Frankfurt. Caracas: Monte Ávila.

Ricoeur, P (1986) Lectures on Ideology and Utopia. Trad. Cast. Ideología y utopía. Barcelona, Gedisa, 1994.

Touraine, A. (1997) Pourrons-nous vivre ensemble? Égaux et différents, Paris: Fayard. (Trans. Cast. M. ARmiño, ¿Podremos vivir juntos? Iguales y diferentes, Madrid: PPC)

ValCÁrcel, A (2002) Ética para un mundo global. Madrid, Temas de Hoy.

VILLORO, L. (1993) «Aproximaciones a una ética del cultura», in Olivé, L. (comp.) Ética y diversidad cultural. México: FCE, 131-154.

Wimmer, F. M. (2004) Interkulturelle Philosophie. Eine Einführung. Viena: WUV Verlag.

Departamento de Filosofía UNED, Madrid.

M ${ }^{\mathrm{a}}$ CARMen López SÁEnZ

clopez@fsof.uned.es

[Artículo aprobado para su publicación en noviembre de 2014] 